\title{
Tempos de fazer, saber e aprender: o Parfor da Universidade de Sorocaba
}

\author{
Vania Regina Boschetti
}

Resumo: Aprender é um exercício constante de renovação, dizia Paulo Freire. A partir desse princípio, o texto tem por objetivos: apresentar o Parfor, seu suporte legal e características de funcionamento, entender o caráter histórico-antropológico da educação, caracterizar a implantação e desenvolvimento do Parfor, na Universidade de Sorocaba, e analisar o Programa à luz dos conceitos pedagógicos relacionados à formação e capacitação docente. A pesquisa realizada no desenrolar do curso, se fez pela observação direta do cotidiano e pela coleta de dados decorrente de pesquisa desenvolvida com alunas e professores que conviveram ao longo do processo de estudo. Procedeu-se análise dos resultados permitindo uma reflexão ampliada sobre a formação de professores à luz da proposta do Parfor, das expectativas das alunas e do trabalho docente.

Palavras-chave: Formação de professores. Parfor. Práticas docentes.

\section{Doing, knowing and learning times: Parfor from University of Sorocaba}

Abstract: Learning is a constant exercise of renewal, said Paulo Freire. From this principle, the text aims: to present the Parfor, its legal support and operating characteristics, to understand how education is important, historically and anthropologically, to characterize the implementation and development of Parfor, at the University of Sorocaba, and to analyze the program under the eyes of pedagogical concepts related to education and teacher training. The research conducted during the course, was done through direct observation of everyday life and through collecting data from the research made with students and teachers who lived together throughout the study process. The analysis of the results was made to allow a wider reflection on teacher training according to Parfor's proposition, the expectations of the students and the work of teachers.

Key words: Teacher training. Parfor. Teaching practices. 


\section{Primeiros indicadores}

Três elementos têm sido constitutivos da ação escolar institucionalizada em todos os tempos: o aluno, o conhecimento e o professor. A cada época interesses diversos, políticas de governo, teorias pedagógicas, alternam a ênfase em algum deles mas, é certo, são indissociáveis no desenrolar do processo educativo. É preciso considerar também que o trabalho docente formal, aquele desenvolvido nas salas de aula no interior das instituições escolares, dotado de particularidades e identidade próprias, tem uma certa complexidade - sistematização, metodologia, reflexão, planejamento específico, produção de experiências. Pode até ser simples. Simples, sim. Simplista nunca. Qualquer prática que se afaste das características citadas, reduz a atividade pedagógica ao casuísmo e à improvisação. Ao docente cabe nessa perspectiva, o cuidado de agir com equilíbrio e parcimônia para a execução de um trabalho educativo sedimentado pela formação, pelo conhecimento pedagógico, pela experiência construída nas interfaces da docência, como afirma Tardif (2002, p. 39) "alguém que deve conhecer sua matéria, sua disciplina e seu programa além de possuir certos conhecimentos relativos às ciências da educação e à pedagogia e desenvolver um saber prático baseado em sua experiência cotidiana com os alunos".

Frente a tais considerações e na perspectiva da pesquisa realizada, a reflexão se desenvolveu em torno da formação docente em nível superior promovida pelo Programa de Formação de Professores - Parfor (MEC-CAPES). A prática docente com as turmas cursando Pedagogia na Universidade de Sorocaba/Uniso, permitiu conhecer os motivos que levaram professores, estagiários e auxiliares de classe a responder à oportunidade de aquisição de credencial acadêmica. Também dimensionou, nos sete semestres do curso, o encontro entre a complexidade da vida universitária, os saberes teóricos e a propostas pedagógicas, com a prática docente construída no cotidiano das escolas onde atuavam e, em quais aspectos, os saberes trazidos pelas alunas em anos de profissão, foram inter-relacionados com os saberes formais do curso de Pedagogia.

\section{O programa de formação de professores - Parfor}

O que é o Parfor? O Plano Nacional de Formação dos Professores da Educação Básica, ainda em vigor no país, é resultado da ação conjunta do Ministério da Educação (MEC) que, pela Plataforma Freire e por intermédio da CAPES (Coordenação de Aperfeiçoamento de Pessoal de Nível Superior), estabelece regime de colaboração com as Secretarias de Educação dos Estados, do Distrito Federal e dos Municípios e com as Instituições de Ensino Superior (IES), no âmbito do PDE - Plano de Metas Compromisso Todos pela Educação. Programa estratégico do PDE/MEC inaugura um novo regime de colaboração, que busca concentrar a atuação das unidades da federação sem ferir-lhes a autonomia, envolvendo primordialmente a decisão política, a ação técnica e o atendimento da demanda educacional, visando à melhoria dos indicadores educacionais. O compromisso fundado em 28 diretrizes e consubstanciado em um plano de metas concretas, efetivas, compartilha competências políticas, técnicas e financeiras para a execução de programas de manutenção e desenvolvimento da educação básica, nos estados que aderem à formação. $\mathrm{O}$ objetivo principal do programa é garantir que os professores em exercício na rede pública de educação básica obtenham a formação exigida pela 
Lei 9394/96, Lei de Diretrizes e Bases da Educação Nacional - LDB, por meio de cursos superiores públicos, gratuitos e de qualidade. As modalidades de cursos oferecidas são:

I. Primeira licenciatura - para docentes em exercício na rede pública da educação básica que não tenham formação superior;

II. Segunda licenciatura - para docentes em exercício na rede pública da educação básica, há pelo menos três anos, em área distinta da sua formação inicial; e

III. Formação pedagógica - para docentes graduados não licenciados que se encontram em exercício na rede pública da educação básica.

O Decreto n. ${ }^{\circ}$ 6.755/2009 da Presidência da República, em seu artigo primeiro, instituiu a Política Nacional de Formação de Profissionais do Magistério da Educação Básica, "com a finalidade de organizar, em regime de colaboração entre a União, os Estados, o Distrito Federal e os Municípios, a formação inicial e continuada dos profissionais do magistério para as redes públicas da educação básica".

De início foram priorizadas as parcerias com as instituições públicas. A participação de instituições não públicas no Parfor tornou-se possível graças a uma alteração no decreto que criou o Plano que retirou uma restrição que havia sido solicitada pela Procuradoria Federal e que impedia a transferência de recursos para instituições privadas. Instituições comunitárias e confessionais de ensino superior puderam então participar. A maior parte delas (16) ingressou no Plano a partir do segundo semestre de 2010, quando foram abertas 39 mil vagas em todo o país ofertando um total de 794 vagas para licenciaturas e pedagogia em São Paulo, Rio Grande do Sul e Santa Catarina, segundo dados do Ministério. A inclusão das comunitárias abriu portas para um novo formato de relacionamento entre a Capes e este segmento do ensino superior privado. Um dos fatores que pesou significativamente para levar as instituições de ensino superior comunitárias de São Paulo para o Parfor foi a mobilização da União Nacional dos Dirigentes Municipais de Educação (Undime) que também colaborou na seleção e nos contatos com as instituições.

Do ponto de vista prático, a dinâmica do Parfor se organiza com funcionalidade: o governo federal - no caso a Capes - por meio de bolsas de estudo vincula os docentes que ministram as aulas e para os coordenadores fornece uma verba de custeio. Às instituições universitárias parceiras cabe oferecer a infraestrutura e proceder o processo seletivo. As secretarias estaduais e municipais de Educação colaboram no equacionamento da demanda e da oferta de vagas e modalidades de cursos. As graduações oferecidas no âmbito do Parfor são exclusivas para professores em exercício na rede pública que não têm grau superior ou que lecionam disciplinas diferentes das de área de formação. A educação está inserida no contexto dos direitos sociais coletivos, como afirma Dias Sobrinho (2005) e, como bem público, deveria estar disponível a todos. O autor amplia a ideia ao estabelecer que um dos imperativos mais fortes da educação, particularmente nos países de grandes e históricas desigualdades como o Brasil, é necessários criar condições e possibilidades que pelo menos minimizem as distorções e se possível, contribuam para a formação de pessoas que além da aquisição cognitiva de bens científicos e culturais, desenvolvam consciência de sentimentos e comportamentos sociais consistentes como equidade, comprometimento, responsabilidade e justiça social. 
O processo educativo se apresenta também como fenômeno histórico em duplo sentido: é referente à história individual de cada ser humano e, vincula-se à fase vivida pela comunidade em sua contínua evolução (CUNHA, 1982). É assim que, utilizando-se dos pressupostos mencionados e voltando o olhar para o Parfor da Universidade de Sorocaba, uma das primeiras universidades comunitárias a entrar no programa em 2010, identifica-se que as alunas de várias cidades da região, há muito tempo atuavam como professoras ou auxiliares de ensino nos berçários, nas creches, nas escolas de educação infantil, tendo ou não formação específica, como irão demonstrar os dados da pesquisa. A apreensão do conhecimento está ligada à experiência do sujeito, à formação da vida social, à construção e apropriação da cultura, à identificação de valores e incorporação de princípios que estabelecem sua ação - expressão de liberdade e criatividade para consolidar a condição humana, como já expresso por Dias Sobrinho (2013). Se conhecimento e educação são bens públicos, quanto mais as instituições educativas expandirem e socializarem suas ações, tanto mais irão cumprir com suas responsabilidades sociais. É assim que ganha expressão a atividade dos alunos e dos professores. Os primeiros porque são envolvidos numa atividade consciente e os segundos, porque adquirem e/ou aprimoram condições epistemológicas e concretas para crescimento pessoal e profissional. A conjugação desses fatores - oportunidade, gratuidade e experiência de trabalho, trouxe as alunas para o curso de Pedagogia/Parfor da Uniso. O curso organizado em 7 semestres letivos é uma das licenciaturas mais conhecidas na cidade e região, respondendo há mais de cinquenta anos, pela formação de professores e especialistas que exercem atividade docente ou correlata, nos sistemas educacionais existentes.

\section{Formação de professores no Brasil: uma breve história}

A formação de professores está ligada à institucionalização da instrução pública. $\mathrm{Na}$ história da educação brasileira, a formação de professores foi realizada entre percalços e instabilidades. As primeiras iniciativas no século XIX em tempos de segundo império estavam limitadas em algumas cidades das províncias. De percurso incerto, se constituíram em instituições carentes de estrutura básica, de definidores, de regulamentação específica e de encaminhamento pedagógico que oferecidas à coletividade de Niterói, Minas Gerais, Bahia, São Paulo entre outras, se estenderam pelo país. Apenas nos anos finais do século XIX passaram a ser espaço escolar para mulheres. Essas escolas, tinham duração instável, fechando e retornando às atividades, mudando o nível de escolarização, o tempo de duração dos cursos e o horário/período de funcionamento. $\mathrm{O}$ descaso pelo formação docente era muito próprio de uma sociedade não comprometida com a educação elementar, que acolhia o professor sem formação, muitas vezes na pessoa de um funcionário público nomeado sem concurso e que não tinha como considerar a questões metodológicas e pedagógicas. As escolas contavam muitas vezes com poucos interessados e ausência de professores. Um exemplo foi a Escola Normal de Niterói (1835-1849) que funcionou precariamente com poucos alunos e um único professor. Pouco se exigia para o exercício do trabalho docente: saber ler e escrever, idade mínima de 18 anos e ter bons costumes. Também se oferecia pouco em termos de salário e de condições didáticas. Os chamados cursos normais, sob responsabilidade dos governos provinciais se desenvolviam no contexto das atividades educativas formais, mas, à mercê das circunstâncias, das políticas ocasionais de governo e da própria instabilidades de sua aplicação. 
Somente em tempos republicanos é que começaram a acontecer mudanças em termos legais e normativos. $\mathrm{O}$ advento dos grupos escolares como instituição sistemática, seriação e identidade educativa, exigiam a presença de profissionais para exercer as atividades de uma escola elementar que se estendia por quatro anos e, pela primeira vez se alicerçava na relação professor-aluno-conhecimento. A formação de professores para atender a demanda trazida pelos grupos escolares, levou à instalação de instituições formadoras. Gradativamente elas foram sendo propostas, inclusive pela iniciativa privada e municipal, e, passaram a existir os primeiros termos legais e normativos em busca de uma organicidade sistemática para a formação docente.

No governo Vargas, a Reforma Capanema ${ }^{1}$ instituiu as Leis Orgânicas do Ensino Normal pelo Decreto-Lei 8.530 de 02/01/1946 (BRASIL, 1946) que caracterizava a organização e duração dos cursos, sua formação e estrutura, programas e atividades, composição do corpo docente, requisitos exigidos aos alunos. Apesar da especificidade, a Lei Orgânica do Ensino Normal instituída pelo Decreto-lei n. 8.530 de 2 de janeiro de 1946, não introduziu grandes inovações apenas evidenciando o propósito de dar alguma uniformidade à formação de professores, com exigências de ingresso, reconhecimento de cursos municipais e particulares, a transferência de alunos. Por ela, a formação de professores adquiriu características de escola profissional ao atrelar sua existência à manutenção a um grupo escolar, um jardim de infância e um ginásio oficialmente reconhecido (TANURI, 2000).

Durante algumas décadas a formação de professores manteve-se como curso de nível médio, com três anos de duração. A denominação "Curso Normal" vigorou até a promulgação da Lei 5.692/71 (BRASIL, 1971) que mudou a denominação para Curso de Magistério. A lei, produto da conjuntura dos governos militares a partir de 1964, pela perspectiva tecnicista, tratava de tornar a escola eficiente e produtiva e, por ela, a escola normal resumia-se ao conceito de habilitação específica para o magistério de $1^{\mathrm{a}}$ a $4^{\mathrm{a}}$ séries e de educação infantil.

A partir da década de 1980, movimentos a favor da "revitalização do ensino normal" (TANURI, 2000, p. 14), desencadeou projetos com a finalidade de dotá-lo de condições adequadas à formação de professores, dos quais a melhor expressão foram os CEFAMs (Centros Específicos de Formação e Aperfeiçoamento do Magistério), que no estado de São Paulo, foi das experiências mais exitosas, mas infelizmente de vida curta.

A Lei 9.394/96 (BRASIL,1996), Lei de Diretrizes e Bases da Educação Nacional $(\mathrm{LDBN})$, em seu artigo 62 veio estabelecer a exigência de nível superior para a formação de professores, "em curso de licenciatura, de graduação plena, em universidades e institutos de educação"... Apesar do princípio legal, o país não o teve acompanhado em oferta e possibilidades o atendimento da exigência. A formação de nível médio, foi desativada em vários lugares, mas em muitos continuou e continua sendo o único recurso de capacitação para aqueles que querem adentrar ao exercício da docência para crianças de zero a dez anos .

O Parfor portanto, se instituiu neste contexto: encaminhamento para dar conta da formação de professores em nível superior nos termos da legislação. A iniciativa para atender inicialmente aqueles que se encontram, na prática, em exercício docente com crianças, sem ter titulação universitária e, muitas vezes sequer formação específica de nível médio. Inserida no

\footnotetext{
1 As Leis Orgânicas, para Tanuri (2000, p. 15), foram a expressão de uma política educacional centralizadora na tentativa de regulamentar a organização e funcionamento de todos os tipos de ensino no país.
} 
Parfor, a Universidade de Sorocaba, instituição comunitária, iniciou seu trabalho com essas alunas em 2010, agregando à experiência de mais de meio século na formação de professores uma nova condição: o encontro entre a complexidade da vida universitária, os saberes teóricos e a propostas pedagógicas, com a prática docente construída por essas alunas no cotidiano de trabalho nas escolas. Em quais aspectos, os saberes trazidos pelas alunas em anos de profissão, foram inter-relacionados com os saberes formais do curso de Pedagogia? Tardif (2000, p. 39), afirma que "o professor ideal é alguém que deve conhecer sua matéria, sua disciplina e seu programa, além de possuir certos conhecimentos relativos às ciências da educação e desenvolver um saber prático baseado em sua experiência cotidiana com os alunos".

Da lógica do raciocínio, pôde-se concluir que a formação do professor, como de outras áreas especializadas, se realiza por meio de um processo gradativo de aquisição de conhecimentos que sustentarão o exercício profissional. Logo, saberes docentes aliados às ações pedagógicas, constituem a base do processo educativo que, abrangendo as dimensões do ser humano, permitirão a professores e alunos evoluir sempre.

Como articular essa concepção à realidade das alunas do Parfor? Como raciocinar na lógica da formação se elas, em sua maioria, apesar de atuarem há tempos nas unidades escolares, o fazem sem ter como desejado, formação específica que balizaria a atuação com crianças do berçário/maternal, educação infantil e ensino fundamental? Dados obtidos pela pesquisa mostram, por exemplo que apenas duas alunas atuam há cinco anos, que quinze das trinta e três, são responsáveis pela turma enquanto as demais, intituladas estagiárias e auxiliares de classe, via de regra, respondem pela docência e todas, indistintamente vem elaborando em práticas espontâneas a experiência da docência.

\section{A pesquisa}

A pesquisa se desenvolveu no cotidiano das atividades docentes ao longo do curso tendo como fonte de referência as duas primeiras turmas. Tratando-se de uma trajetória inédita para alunas, docentes e instituição, das primeiras preocupações fizeram parte o conhecimento e a observação desse momento novo e de como se constituiria a dinâmica com processo acadêmico. Fatores objetivos e subjetivos permitiram constituir um corpo ideias e percepções do que foi se delimitando como período de formação na perspectiva pessoal e profissional. O trabalho docente com as turmas em salas de aula e fora delas, delineou perfis de três grupos quanto às expectativas e resistências, ansiedade e empenho, possibilidades e limites. Em decorrência de tais características os grupos puderam ser assim representados: um majoritário para quem a oportunidade de estudos mais avançados concretizava planos e anseios desejados e deveria ser apreendida independentemente dos "custos"; outro para quem um Programa constituído por um sistema de bolsas e liberação de verbas públicas, não beneficiava apenas alunos, mas profissionais da educação e a universidade parceira, por isso implicava em atenção para o uso das verbas e das práticas docentes, o que, em caso da não satisfação com os resultados, seria sempre passível de cobrança e denúncia; um terceiro grupo se matriculou como tentativa: cursar enquanto pudesse fazer frente às exigências pessoais e acadêmicas de realização.

Posteriormente foram utilizados instrumentos de pesquisa formais por meio de dois questionários: um para as alunas outro para os docentes do Programa. Constituídos de duas 
partes, apontaram na primeira parte da coleta, dados objetivos pessoais e profissionais obtidos por conjunto de questões direcionadas apresentando alternativas. Uma segunda constituída de questões abertas e de livre expressão. Trinta e três alunas responderam, anônima e espontaneamente. Explicou-se às alunas em classe e antes de entregar os questionários a finalidade da pesquisa e a não obrigatoriedade de adesão - quem não quisesse responder poderia deixar a sala ou devolver a folha não preenchida, colocando-a juntamente com as demais no envelope que estava sobre a mesa.

Aos professores foi entregue o questionário individualmente, em envelope. Os questionários eram precedidos de breve nota explicativa sobre o que estava sendo feito e, a devolução, no mesmo envelope fechado, feita à funcionária da sala dos professores da Universidade. Vinte dois questionários foram entregues e dezenove devolvidos. Procedeu-se ao levantamento dos dados e o agrupamento das variáveis apresentadas pelas respostas pessoais relacionadas às experiências, impressões e conceitos.

As primeiras respostas permitiram emergir um quadro pontual dimensionando o perfil das alunas: maioria com mais de 30 anos, trabalhando com educação infantil na rede municipal, como estagiárias concursadas. Apenas duas das alunas trabalham em escolas particulares de seus municípios.

Quadro 1 - Dados gerais e pessoais

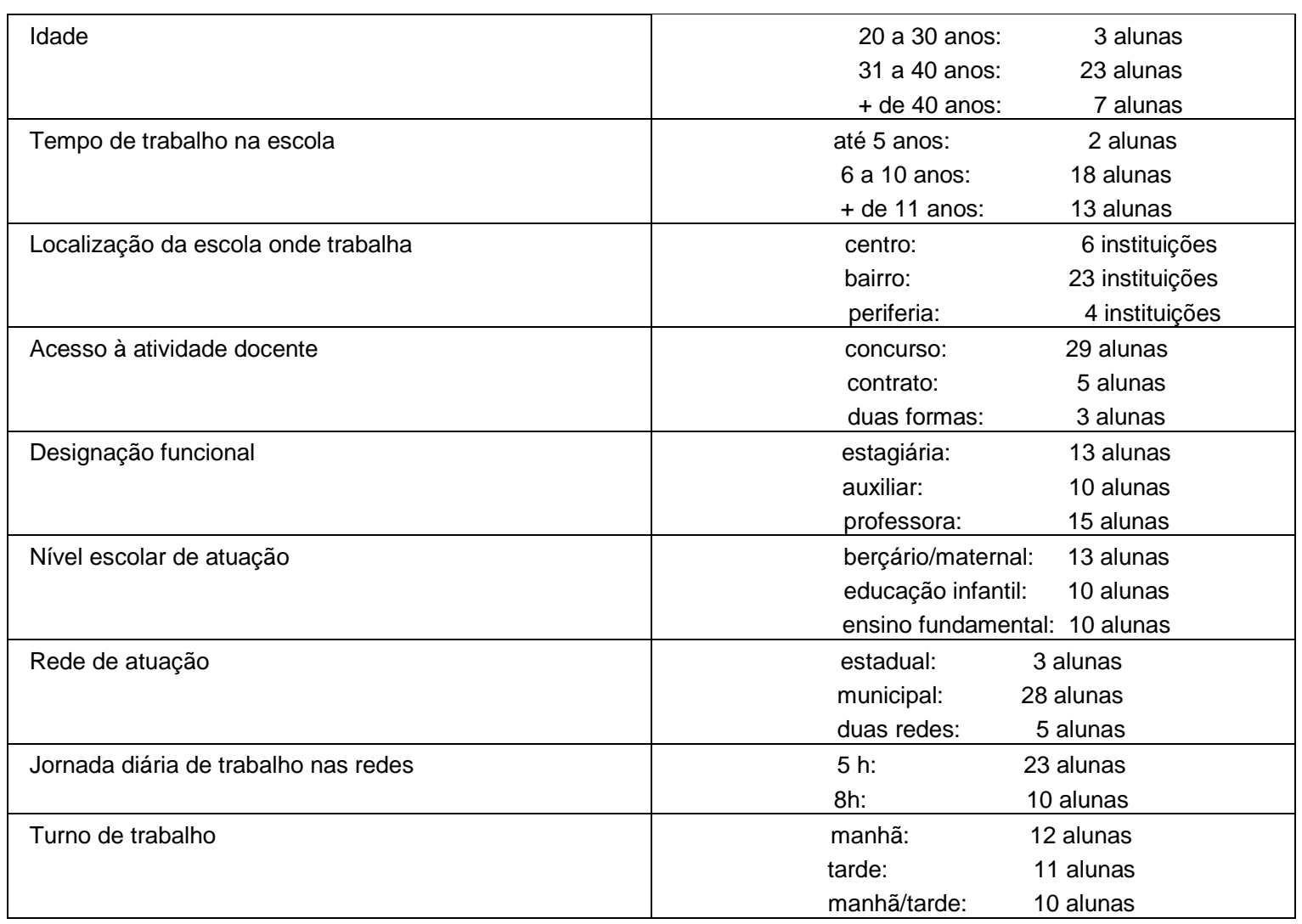

Há uma similaridade de condições gerais: idade, formação, ao ritmo de trabalho. Esses elementos de similaridade irão manter presença na continuidade da investigação. O levantamento de escolarização identificou as alunas como egressas do ensino médio público, a metade vinda do magistério (escola normal), as demais escolarização convencional ( $2^{\circ}$ grau/ensino 
médio) e, com práticas profissionais anteriores bastante diversificadas. Há casos com duas atividades produtivas concomitantes. A formação superior de seis alunas é diversificada: Administração de Empresas, Processamento de Dados, Letras, Gestão Pessoal, Gestão de RH e História e realizada em instituições particulares. As que cursaram bacharelados não exerceram a profissão por falta de oportunidades no mercado de trabalho. Atuar na rede escolar se apresentou como opção para uma atividade remunerada.

\section{Quadro 2 - Formação e trabalho}

\begin{tabular}{|c|lc|}
\hline Escolarização & ensino médio público: & 13 alunas \\
& supletivo público: & 4 alunas \\
& normal/magistério: & 16 alunas \\
& ensino particular: & 6 alunas \\
& ensino superior: & 6 alunas \\
\hline Atuação profissional anterior & atividade doméstica: & 6 alunas \\
& vendas: & 2 alunas \\
& industrial: & 3 alunas \\
& comercial: & 12 alunas \\
& área da saúde: & 3 alunas \\
& diversas: & 4 alunas \\
\hline
\end{tabular}

A atividade doméstica assinalada diz respeito tanto àquela realizada na própria casa quanto em casa de outro. A atividade comercial, de maior concentração, abrigou ( e ainda abriga), significativamente, a atividade informal da venda por catálogos, artigos estrangeiros, bijuterias e roupas, feitas à domicílio e no próprio âmbito do trabalho.

O quadro a seguir apresenta as dificuldades encontradas pelas alunas. Das maiores estão o tempo para execução das responsabilidades e a distância. O deslocamento à Sorocaba foi apontado como maior obstáculo. Moradoras das cidades da região da como Araçoiaba da Serra, Itu, Ibiúna, Mairinque, Porto Feliz, Piedade, São Roque, Salto, Tietê e Votorantim, explicaram que, além da estrada, precisam enfrentar a chegada tarde da noite. Problema maior para moradoras de bairro afastado ou da zona rural. À jornada diária de trabalho, deslocamentos e estudos nunca inferior a oito horas, provocando sono e cansaço como consequências naturais sobre um corpo de quem se exige esforço físico e mental (mal de que padecem todos os trabalhadores que estudam). Os custos com transporte representaram ônus adicional para as moradoras de municípios sem transporte gratuito para as viagens diárias. A grande maioria cobrava-se (é também era cobrada) pelas ausências do convívio familiar e atenção aos filhos. Conciliar essas adversidades com a vida acadêmica não foi fácil, mas diziam elas ter sido compensador, "pela oportunidade de crescimento e pela realização do sonho de estudar".

A sequência da pesquisa adentrou à investigação das dificuldades encontradas para realizar o percurso universitário de sete semestres. Oriundas dos segmentos sociais mais populares, moradoras de cidades pequenas, algumas da área rural, tiveram como condição de estudos o ensino fundamental e médio convencional (disponível no espaço de moradia), ou mesmo curso supletivo. Constituíram família rapidamente e trabalhar nas escolas e creches, se apresentou como possibilidade de ganho regular e bom ambiente de trabalho, situação com maior estabilidade se forem considerados os recursos de trabalho/rentabilidade praticados antes da atividade nas escolas. As dificuldades do cotidiano estiveram sempre presentes. Parte delas acompanhando o dia à dia chegando à universidade. Para melhor entendimento e reflexão, o 
questionário foi constituído por três questões abertas que ofereciam possibilidades de ampliar a argumentação, exposição do pensamento e experiências pessoais e profissionais que afloraram durante o curso.

Quadro 3 - Dificuldades encontradas pelas alunas para fazer o curso

\begin{tabular}{|l|c|}
\hline Tempo com deslocamentos, custos de transporte, distância & 19 alunas \\
\hline Pouco tempo para estudo e para conciliar trabalhos/estudo & 15 alunas \\
\hline Questões familiares: compreensão, atendimento aos filhos... & 12 alunas \\
\hline Desgaste físico (sono, cansaço, correrias...) e emocional & 10 alunas \\
\hline Insegurança para executar os trabalhos acadêmicos & 5 alunas \\
\hline Adequação à rotina acadêmica & 5 alunas \\
\hline Entendimento dos conteúdos & 5 alunas \\
\hline
\end{tabular}

Fatores como oportunidade, gratuidade e experiência de trabalho permitiram às alunas cursar Pedagogia. Tais facilidades porém, não tiraram a clareza para apontar necessidades de melhoras e de fazer a crítica de algumas situações pontuais, algumas até improcedentes como subir escadas e frequência obrigatória. Aqui é conveniente reportar-se àquele grupo de alunas para quem "um Programa constituído por um sistema de bolsas e liberação de verbas públicas, não beneficiava apenas alunos, mas profissionais da educação e à universidade parceira, implicava, em caso da não satisfação, a possibilidade de cobranças variadas", como já abordado no início do artigo. Outro fator importante a considerar foi a relação dessas dificuldades e a desistência do curso. Dados oficiais do SAA (Serviço de Atendimento ao Aluno), apontaram os seguintes números: dos 74 ingressos em 2010, 35 alunas concluíram o curso em 2013 e duas alunas , cursam dependência no curso regular agora em 2015. A evasão da primeira turma tangenciou os 50\%. Da turma de 31 alunas ingressantes em 2011, 21 concluíram, 6 evadiram e 4 cursam dependência também em 2015. Informalmente as razões para esses números em sua maciça maioria, apontam para os problemas pessoais de diversas ordens como saúde, inviabilidade de arcar com os custos, questões familiares, desinteresse. Uma das argumentações foi enfática: "a grande dificuldade foi administrar fatos da vida social, financeira e afetiva com a faculdade". Falta de capacidade para acompanhar o curso foi apontada uma única vez como causa provável. Convém observar que nenhum dos aspectos apontados como negativos, no quadro a seguir, foram considerados como dificuldades para a realização dos estudos.

\section{Quadro 4 - Aspectos negativos do curso ( até cinco)}

\begin{tabular}{|l|c|}
\hline Distanciamento com a coordenação* & 9 alunas \\
\hline Alguns professores com metodologia ultrapassada & 9 alunas \\
\hline Espaço físico com restrições: classe no último andar, escadas, carteiras & 6 alunas \\
\hline Falta de clareza da Secretaria & 4 alunas \\
\hline Problemas com equipamentos: vírus, internet lenta, data show & 2 alunas \\
\hline Rigidez nos prazos de entrega dos trabalhos & 2 alunas \\
\hline Curso noturno presencial & 1 aluna \\
\hline Excesso de trabalhos acadêmicos & 1 aluna \\
\hline Alguns conceitos pouco explorados & 1 aluna \\
\hline Não apontaram aspectos negativos & 5 alunas \\
\hline
\end{tabular}


* Deve-se ressalvar aqui que não foi especificada a que coordenação se referiam. A organização do Parfor/Uniso tem duas coordenações: uma geral, administrativa, na figura de um assessor que fazia a interlocução com os órgãos federais (MEC-CAPES) e, outra, na figura da coordenação do curso de Pedagogia, a quem se reportavam nas questões acadêmicas. À coordenação geral cabia a responsabilidade das questões administrativas do programa: organizar infraestrutura de funcionamento, atendimento burocrático, tomada de decisões em função das emergências e dispositivos legais, liberação de verbas, encaminhamento de pesquisas orçamentárias para aquisição de material didático e atividades extraclasse, finalização de relatórios. A coordenação do curso de Pedagogia respondia pelas funções pedagógicas: acompanhamento do curso em sua rotina universitária, composição e seleção do corpo docente, atribuição de aulas, atendimento aos alunos e professores, organização do oficina pedagógica, encaminhamento para a realização de atividades extras. Coordenação do curso, professores do Programa e representação discente, constituíram um colegiado que se reunia mensalmente, repetindo o mesmo procedimento existente no curso regular de Pedagogia.

\section{Quadro 5 - Aspectos positivos do curso ( até cinco)}

\begin{tabular}{|l|l|}
\hline Professores preparados, competentes e comprometidos & 20 alunas \\
\hline Estrutura universitária & 9 alunas \\
\hline Recursos didáticos & 9 alunas \\
\hline Biblioteca & 8 alunas \\
\hline Atividades culturais externas & 8 alunas \\
\hline Conteúdos variados, consistentes e atuais & 8 alunas \\
\hline Oportunidade de novas experiências pessoais & 7 alunas \\
\hline Incentivo dos professores & 5 alunas \\
\hline Curso frequencial, de qualidade e gratuito & 4 alunas \\
\hline Socialização entre professores e alunos & 3 alunas \\
\hline Uso de metodologias dinâmicas & 3 alunas \\
\hline Matriz curricular apropriada & 2 alunas \\
\hline
\end{tabular}

A manifestação das alunas quanto ao corpo docente, pode ser explicada a partir dos próprios dispositivos da instituição e do curso que as acolheu: todos os professores bolsistas da Capes atuando no curso, são mestres ou doutores e com larga experiência de vida profissional, como será identificado posteriormente pelos dados de pesquisa docente. Quanto à metodologia, o curso proporcionou a oportunidade de valorização da vivência educativa do professor-aluno e, para isso, o conceito de educação permanente permeou as dinâmicas, como atividade consciente direcionada para a mudança; pressupondo a educação para além da escola "preparando o professor para participar da vida social, política, cultural e artística, pois os professores não se apoiam em um único saber para ensinar, mas em vários” (BORGES, 2004, p. 260). Para que esses objetivos fossem alcançados, a formação envolveu teoria e prática, no conceito de Pinto e Ferreira (2013), os dois coordenadores do Programa.

A participação dos professores ampliou as possibilidades de conhecimento do Parfor/Uniso e a sua identificação. Foram contatados vinte e um professores e dezenove devolveram os questionários devidamente respondidos. Procedeu-se de modo similar aquele utilizado com as alunas; informação preliminar dos objetivos da pesquisa, anonimato, impessoalidade no recolhimento das folhas de respostas que deveriam ser colocadas em envelope sem identi- 
ficação, disponível numa das mesas da sala dos professores, para serem arregimentados por uma funcionária que efetuou a entrega à pesquisadora.

Quanto à titulação, experiência educativa e tempo de serviço os dezenove professores apresentavam o seguinte quadro:

Quadro 6 - Professores

\begin{tabular}{|l|ll|}
\hline \multirow{2}{*}{ Titulação acadêmica } & Mestres: & 14 professores \\
\cline { 2 - 3 } Atividades educativas além da docência & Doutores: & 5 professores \\
\cline { 2 - 3 } & Coordenação: 4 professores \\
\cline { 2 - 3 } & Gestão: & 4 professores \\
\cline { 2 - 3 } & Supervisão: & 2 professores \\
\cline { 2 - 3 } & Dirigente: & 2 professores \\
\cline { 2 - 3 } Tempo de serviço & Consultoria: & 1 professor \\
\cline { 2 - 3 } & 2 a 6 anos: 3 professores \\
\cline { 2 - 3 } & 10 a 20 anos: 6 professores \\
\cline { 2 - 3 } & 25 a 30 anos: & 4 professores \\
& de 35 anos: & 6 professores \\
\hline
\end{tabular}

O corpo docente, portanto, constituído de profissionais de competência teórica advinda dos cursos universitários e de expressiva experiência profissional. Levar para a sala de aula situações do exercício educativo praticado na direção das escolas, na supervisão das instituições públicas e privadas, na coordenação das atividades pedagógicas e das exigências de comando das diretorias de Ensino, agregou valor a um curso que teve na esfera da educação permanente e na articulação teoria-prática, fatores de relevância, principalmente se forem consideradas "as condições de trabalho, as salas superlotadas, os baixos salários predominantes, a dificuldade em realizar atualizações de conteúdo...” (SCHEIBE, 2010, p. 984).

Como afirma Tardif (2002), são muitas habilidades profissionais que demarcam a especificidade da ação docente e, considerando ainda que o ambiente de trabalho das alunas era predominantemente nos níveis de educação infantil e ensino fundamental, pôde-se avaliar o quanto oportuno foi adentrar ao universo profissional expandido.

Questões abertas foram propostas aos professores: elencar até quatro aspectos positivos e até quatro aspectos dificultadores do Programa Parfor e identificar valores adquiridos na perspectiva profissional.

As respostas foram agrupadas de acordo com a similaridade de percepção e atuação constituíram os seguintes quadros:

\section{Quadro 7 - Aspectos positivos}

\begin{tabular}{|l|c|}
\hline Comprometimento de professores e alunas & 10 professores \\
\hline Troca de experiências & 9 professores \\
\hline Oportunidade de experiência acadêmica & 8 professores \\
\hline Discussão das realidades vivenciadas no trabalho & 8 professores \\
\hline Oportunidade de estudo e formação & 8 professores \\
\hline Compromisso com o trabalho educativo & 7 professores \\
\hline Preocupação com o crescimento pessoal e profissional & 6 professores \\
\hline Convivência e cooperação & 4 professores \\
\hline
\end{tabular}


Quadro 8 - Aspectos dificultadores

\begin{tabular}{|l|l|}
\hline Atrasos, faltas constantes, resistência à frequência & 16 professores \\
\hline Limites ao entendimento teórico & 11 professores \\
\hline Cansaço pelo longo dia de trabalho & 9 professores \\
\hline Conflitos entre teoria e as atividades do cotidiano escolar & 7 professores \\
\hline Pouco tempo para estudos (leituras e trabalhos acadêmicos) & 6 professores \\
\hline Distância & 6 professores \\
\hline Distanciamento do curso anterior (muito tempo sem estudar) & 4 professores \\
\hline Dificuldade de participação em atividades extras & 4 professores \\
\hline Falta de conhecimentos prévios & 2 professores \\
\hline Dificuldades para apresentação de trabalhos & 2 professores \\
\hline
\end{tabular}

Do conjunto dos professores atuantes no Parfor, três trabalharam apenas um semestre com o grupo; seis dois semestres; seis, três semestres e também seis, por quatro semestres. A constância facilitou o contato, o conhecimento e a interrelação entre alunas/ professoras e a continuidade de projetos. Professores e alunas integrados, reelaborando continuamente significados e informações puderam construir representações do consideraram adequado, pertinente, esperado ou não no desenrolar dos trabalhos e dos limites encontrados.

[...] saberes profissionais dos professores não são somente personalizados, eles também são situados, isto é, como dizíamos anteriormente, construídos e utilizados em função de uma situação de trabalho particular, e é em relação a essa situação particular que eles ganham sentido. Em outras palavras, diferentemente dos conhecimentos universitários, os saberes profissionais não são construídos e utilizados em função de seu potencial de transferência e de generalização; eles estão encravados, embutidos, encerrados em uma situação de trabalho à qual devem atender [..] poderíamos falar aqui de "contextualidade" dos saberes profissionais. Ora, no ensino, esse fenômeno é de suma importância, pois as situações de trabalho colocam na presença uns dos outros seres humanos que devem negociar e compreender juntos o significado de seu trabalho coletivo. Essa compreensão comum supõe que os significados atribuídos pelos professores e pelos alunos às situações de ensino sejam elaborados e partilhados dentro dessas próprias situações; noutras palavras, eles estão ancorados, situados nas situações que ajudam a definir [..] O objeto do trabalho do docente são seres humanos e, por conseguinte, os saberes dos professores carregam as marcas do ser humano (TANURI, 2000, p. 16).

É importante buscar o entendimento da "problemática que envolve os docentes entre saberes e práticas" (DONATO; ENS, 2008, p. 155), entre necessidades, interesses e possibilidades na formação dos profissionais. A clareza dessas situações complexas, foram fonte importante inclusive, para a constituição de um perfil do trabalho docente.

A última pergunta da pesquisa, aberta e sem indicações de numerário, solicitava as alunas, indicação das "contribuições para o seu desenvolvimento pessoal e profissional". Três alunas não responderam. Algumas respostas foram exclusivas: "ajudou a passar no concurso", "aprendi que não há verdade absoluta" ou simplesmente "valeu a pena", "irá ajudar na mudança de nível funcional". Genericamente evidenciou-se uma satisfação pessoal ligada às expectativas de vida que se concretizaram e uma clareza relacionada à capacidade de superação 
dos obstáculos. A maioria foi pródiga ao considerar o que identificaram o "o antes e o depois do Parfor". Delimitando as respostas pela constância das respostas, o quadro abaixo especifica:

Quadro 9 - Contribuições para o desenvolvimento pessoal e profissional

\begin{tabular}{|l|c|}
\hline Desenvolvimento pessoal & 14 alunas \\
\hline Aquisição de novos conhecimentos & 10 alunas \\
\hline Aquisição de postura profissional & 12 alunas \\
\hline União entre teoria e a prática & 8 alunas \\
\hline Segurança nas atividades profissionais & 8 alunas \\
\hline Sair do senso comum & 6 alunas \\
\hline Desenvolver ação refletida & 6 alunas \\
\hline Aprimorou conhecimentos da prática & 6 alunas \\
\hline Aquisição de conhecimentos qualificados & 6 alunas \\
\hline Melhor preparo para o ensino e a pesquisa & 5 alunas \\
\hline Despertou a vontade de continuar, ir além & 4 alunas \\
\hline Realização de um sonho & 3 alunas \\
\hline Vantagens no plano de carreira & 2 alunas \\
\hline
\end{tabular}

As colocações foram predominantemente de ordem subjetiva e apontaram a capacidade de buscar elementos para explicar como foram absorvidas as situações variáveis da experiência acadêmica. "Em educação existem vários determinantes que afetam a ação docente [...] mas é de um profissional qualificado e atualizado, consciente de seu papel, determinante na construção de uma sociedade mais justa, [...] que estamos querendo ver atuando nas escolas brasileiras" (DONATO; ENS, 2008, p. 166).

\section{Considerações finais}

As demandas pela formação de professores e a implementação de diretrizes para a docência requerem responsabilidade dos órgãos competentes e seriedade das instituições que se colocam na empreitada de organizar cursos e atender as exigências da formação. A história da educação mostra com clareza de análise e de números que os cursos oferecidos para a formação de professores, demoraram a se constituir em realidade no país e estiveram abaixo da demanda, faltando-lhes organicidade, obediência aos preceitos legais, interesse das políticas de governo. Ainda hoje e de acordo com Scheibe (2010, p. 984) "as pesquisas sobre a formação de professor revelam exaustivamente uma série de problemas e desafios para a elevação do estatuto socioeconômico da categoria [...] deteriorização das condições de trabalho [...] dificuldade em realizar atualizações de conteúdo e metodologias"...

A formação de professores em nível superior ainda é um objetivo a ser atingido, uma meta a ser cumprida, não só em relação aos propósitos e prazos, mas as estratégias de ação, a presença efetiva de oferta pública de cursos superiores para a formação docente e ações articuladas entre quem forma e quem admite o docente. Uma dessas ações, o Parfor, instituído pelo Decreto $n^{\circ} 6.755$, tem se apresentado como possibilidade de "suprir a defasagem de for- 
mação e de valorização do trabalho docente, para professores sem graduação, licenciados que atuam fora de sua área de formação pedagógica e para bacharéis atuantes no ensino.

A participação de instituições comunitárias no Parfor, colocou a Universidade de Sorocaba no rol da instituições parceiras desse objetivo, logo em 2010. Nessa experiência, inovadora para a universidade, pôde-se constatar mais uma vez sua estrita relação com a comunidade regional, o compromisso com a educação e os resultados de suas práticas e de seus serviços vinculados ao ensino, à pesquisa e à extensão. Tradicionalmente oferecendo cursos de licenciatura desde 1954 e com corpo docente titulado e experiente no contexto educacional, a instituição aderiu ao programa. Apesar desses pressupostos o Parfor, em Sorocaba, não conseguiu dar continuidade ao processo de formação. Formou três turmas com alunas advindas da região (uma única da cidade). Apresentou, particularmente com o primeiro grupo de matriculadas, alto índice de evasão. Como se trata de um programa que envolve interação de variadas frentes de ação (estagiários, prefeituras, universidades, política partidária, recursos financeiros) a Uniso, apesar do empenho não conseguiu adensar a procura e, por número reduzido de interessados não prosseguiu parceira do Parfor.

As práticas docentes no desenrolar dos sete semestres do curso se apresentaram na interface da problematização pedagógica, na reflexão das teorias, no embate de situações mais complexas, na apreensão de questões distantes daquelas vivenciadas na concretude no cotidiano escolar de origem das alunas e professores. Foram canais para um novo olhar sobre educação, escola, trabalho docente. A partir desses pressupostos, o Parfor permitiu a valorização da vivência educativa da professora-aluna pela valorização de suas práticas e a articulação possível com as ciências da educação, mostrando que a relação teoria/prática não só é desejável mas, pedagogicamente possível.

A pesquisa permitiu identificar conflitos entre anseios/ possibilidades; teoria/prática; espontaneísmo/ação consciente; continuísmo/renovação de ideias e ações. Confirmou, no imediato da realidade educacional brasileira mais próxima, os limites e percalços para a continuidade de estudos dos segmentos populares da sociedade, esses mesmos segmentos que tem aportado às escolas (particularmente às de educação infantil) para a realização do trabalho docente, mesmo sem ter o devido preparo para tanto.

Pode-se afirmar que a ação do professor nas escolas, muitas vezes é refém de determinismos e determinações. É neles que o professor alicerça seu trabalho, constrói com a experiência os fundamentos da ação educativa. É preciso considerar, entretanto, que manter-se nesse patamar não é suficiente e "não pode estar acima da compreensão de que é necessário aprimorar o estudo dos que se formam como docentes e que uma formação básica integral anterior as início do processo de profissionalização não é dispensável” (SCHEIBE, 2010, p. 994).

O trabalho docente se faz pela prática mas deve ultrapassá-la para que sua eficácia possa se manifestar à luz do entendimento na complexidade das situações que envolve a escola e seus integrantes mais singulares. Toda vez que esses saberes da experiência estiverem interagindo com a escolarização pessoal, com a aquisição de conceitos, com a análise de resultados, compreensão racional do contexto educativo, tanto mais próximo o professor estará da possibilidade de se constituir num profissional qualificado, atualizado, consciente de suas responsabilidades pessoais e profissionais. 


\section{Referências}

BORGES, Cecília Maria Ferreira. O professor da educação básica e seus saberes profissionais. Araraquara: JM Editora, 2004.

BRASIL. Decreto-lei n. 8.530/ 1946. Lei Orgânica do Ensino Normal. Diário Oficial da União, seção 1, p. 116, de 04/01/1946.

BRASIL. Lei n ${ }^{\circ} 5692 / 1971$. Fixa Diretrizes e Bases para o ensino de $1^{\circ}$ e $2^{\circ}$ graus, e dá outras providências. Diário Oficial da União, Brasília, seção 1, p. 6377, de 12 ago. 1971.

BRASIL. Lei no 9394/1996. Estabelece as diretrizes e bases da educação nacional. Diário Oficial da União, Brasília, seção 1, p. 27833, de 23 dez.1996.

BRASIL. Decreto n ${ }^{\circ}$ 6.755/2009. Institui a Política Nacional de Formação de Profissionais do Magistério da Educação Básica, disciplina a atuação da Coordenação de Aperfeiçoamento de Pessoal de Nível Superior -CAPES no fomento a programas de formação inicial e continuada, e dá outras providências. Diário Oficial da União, Brasília, seção 1, de 30 jan. 2009.

CUNHA, Maria Isabel. O bom professor e sua prática. Campinas: Papirus, 1982.

DIAS SOBRINHO, José. Educação Superior: bem público, equidade e democratização. Avaliação, Campinas, Sorocaba, v. 18, n. 1, p. 107-126, mar. 2013. Disponível em: $<$ http://www.scielo.br/scielo.php?pid=S1414$40772013000100007 \&$ script $=$ sci_abstract\&tlng $=$ pt $>$.

DONATO, Sueli Pereira; ENS, Romilda Teodora. A docência entre saberes docentes e práticas. Disponível em: <www.pucpr.br/eventos/educere/educere/2008/anais/pdf/192_353.pdf>. Acesso em: 18 dez. 2014.

PINTO, Rafael Bunhi; FERREIRA, Valdelice Borghi. A implantação do Plano Nacional de Formação de professores (Parfor) em uma universidade comunitária. Revista de Educação do Cogeime, São Paulo, v. 22, n. 42, jan./jun. 2013. Disponível em: $<$ https://www.redemetodista.edu.br/revistas/revistascogeime/index.php/COGEIME/article/view/104>

SCHEIBE, Leda. Valorização e formação dos professores para a educação básica: questões desafiadoras para um novo Plano Nacional de Educação. Educação e Sociedade, Campinas, v. 31, n. 112, p. 981-1000, jul./set. 2010.

TARDIF, Maurice Saberes profissionais dos professores e conhecimentos universitários. Revista Brasileira de Educação, Rio de Janeiro, n. 13, p. 5-24, jan./abr. 2000.

TARDIF, Maurice. Saberes docentes e formação profissional. Petrópolis: Vozes 2002.

TANURI, Leonor Maria. História da formação de professores. Revista Brasileira de Educação, Rio de Janeiro, n. 14, maio/ago. 2000.

Vania Regina Boschetti - Universidade de Sorocaba Sorocaba | SP | Brasil. Contato: vania.boschetti@ prof.uniso.br 